\author{
Jolanta Korycka-Skorupa \\ University of Warsaw - Faculty of Geography and Regional Studies - Chair of Cartography \\ 00-927 Warsaw, Krakowskie Przedmieście 30 \\ e-mail: j.skorupa@uw.edu.pl
}

\title{
UNUSUAL GRAPHIC SOLUTIONS AND THEIR PLACE IN CLASSIFICATION OF CARTOGRAPHIC PRESENTATION METHODS
}

\begin{abstract}
Examples of unusual and unconventional graphic solutions which we can often find in the times of fast developing computer technology are discussed in the article. Many of them are suggested by various GIS programs, few of them may be found in the press or on the Internet. This means that their users are people who are not associated with cartography and who are not familiar with the framework of cartographic methods.
\end{abstract}

Key words: visualisation, cartographic presentation methods, ordinal methods, choropleth map

The fast development of computer technology caused the very dynamic development of various scientific fields, including cartography. The quality of maps published nowadays has increased and the time of their elaborating has shortened. General access to various programs enables their users to edit maps. But these users are not only the cartographers but often they are people who do not have the basic knowledge of cartography. This causes new, unconventional and not always methodologically correct graphic solutions. Quite often, they are the reason for discussions about the methods we use to show different information on maps.

There is agreement between cartographers that numerous available ways of presentation (i.e. prof. L. Ratajski's classification of cartographic presentation methods - 1989) are continuously broadening. - Every single time we open a new edition of an atlas, read newspapers 
or use the Internet we meet a cartographic "novelty", unconventional, unusual or even arguable.

The beginning of every cartographic presentation is to collect a database which is necessary to present a definite subject and to adapt it to a specific cartographic presentation. In fig, 1 there is a scheme which shows the transition from data to the cartographic presentation process (J. Korycka-Skorupa 2002 a, b).

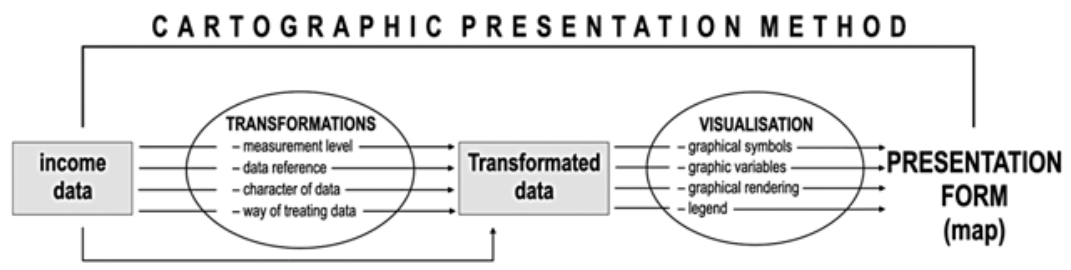

Fig. 1. From data to cartographic presentation forms

In the transformation stage (data adaptation) we may:

- change the data measurement level (by reducing quality data into ordinal data, that is by changing numbers which describe situations into a category like: little, average, many),

- change the data reference (i.e. data which are collected in points may be counted in reference to a precise surface),

- change the character of data (i.e. absolute data can be related to another element, next we receive relative data),

- change the way of treating data: change the data base into a distributive series (to group them into classes).

The data base prepared for a presentation will be visualized next. At this stage, the map editor decides which graphic symbols are to be used, e.g. points, lines or surfaces, which graphic variables are the most suitable for this presentation, e.g. brightness, colour, shape, orientation or size. Finally, he decides if the presentation ought to be presented continuously, or discreet (graphical render ing). At this stage the legend is elaborated.

Transition through the scheme which is presented in picture 1 effects the cartographic presentation form. The obtained graphic picture (a map) is referred to as the presentation form. On the other hand, the method is the procedure of transition to the map. Very often reference is made to prof. Lech Ratajski's classification of presentation methods in Polish 
cartography. He has distinguished seven basic cartographic methods (forms). He arranged them into quantitative forms, i.e. dot map, choropleth map, graduated symbol map and isopleth map and into a qualitative presentation, i.e. symbol map, aerial map and coverage map.

During analysis of maps which are in books, atlases, on the Internet or in the press (see: P. Kowalski Cartographic methods and their correctness on maps in the Polish press since the mid-19 $9^{\text {th }}$ century in this volume) it is easy to notice the quite casual approach to the cartographic presentation methods. Probably this results from the fact that authors of these maps are not always cartographers. In the meantime, a defined map presentation form is the consequence of meeting certain conditions which should have been known by the map editors.

In prof. L. Ratajski's classification of cartographic presentation methods nothing was said about ordinal methods, about presentation of data which determine specific phenomena, such as small, average or big. Nowadays, ordinal data are very often used on the maps and cartographers accepted this fact and describe these methods as ordinal. Therefore, we may speak of ordinal diagrams (Fig. 2), ordinal choropleth map (Fig. 3), or even isopleth map expressed in this way (Fig. 4).

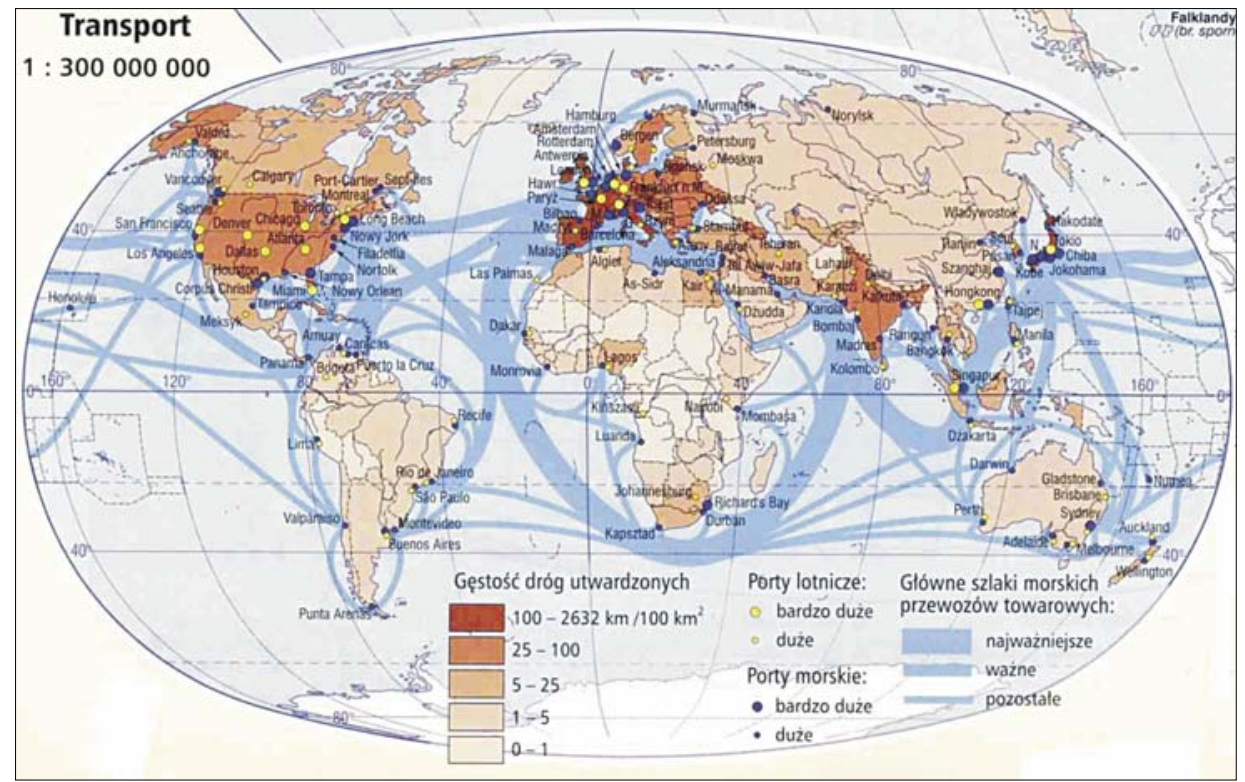

Fig. 2. Ordinal flow diagram map 


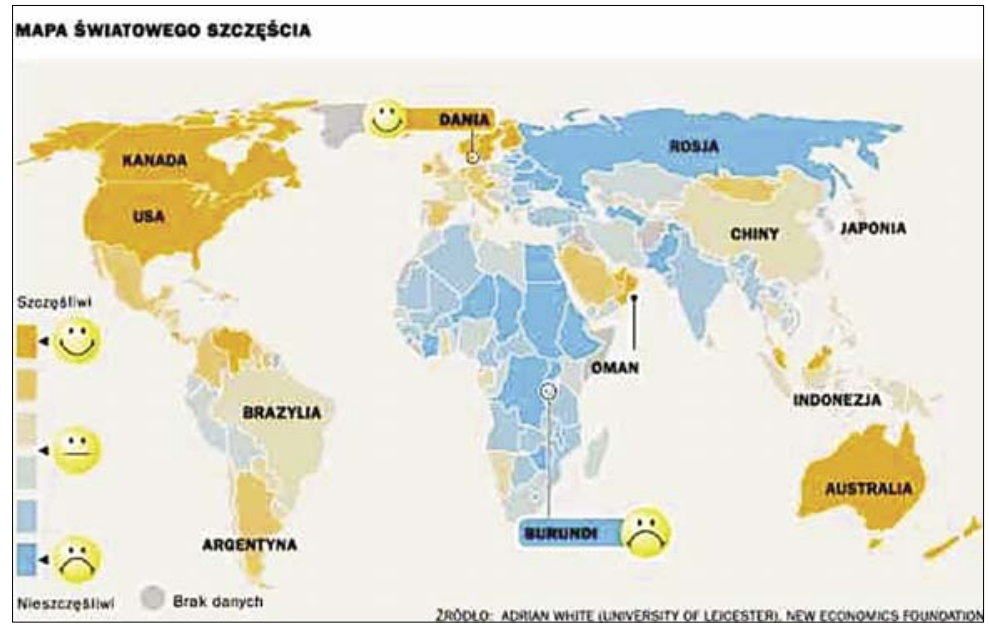

Fig. 3. Choropleth map according to ordinal classes

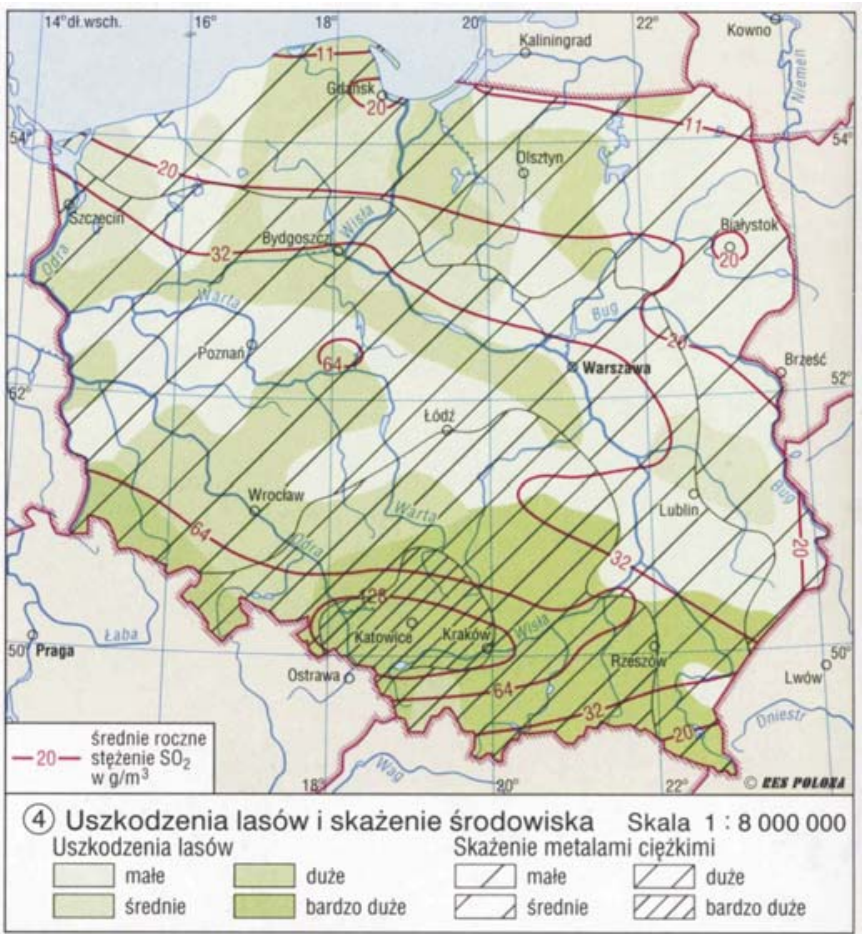

Fig. 4. Ordinal isopleth map 
Such presentation does not stem from a lack of ability to show quantitative data on maps. Rather, it is an attempt to sidestep the often complicated numbers and to replace them with ordinal expressions which are definitely easier to remember. In school atlases, which are dedicated for different levels of teaching, we may find the same maps but with different descriptions, i.e. in ordinal or quantitative manner, depending on the teaching level (Fig. 5). Thus, students of lower school levels receive a map which is easier to read. Older students may learn from a map with more precise information.

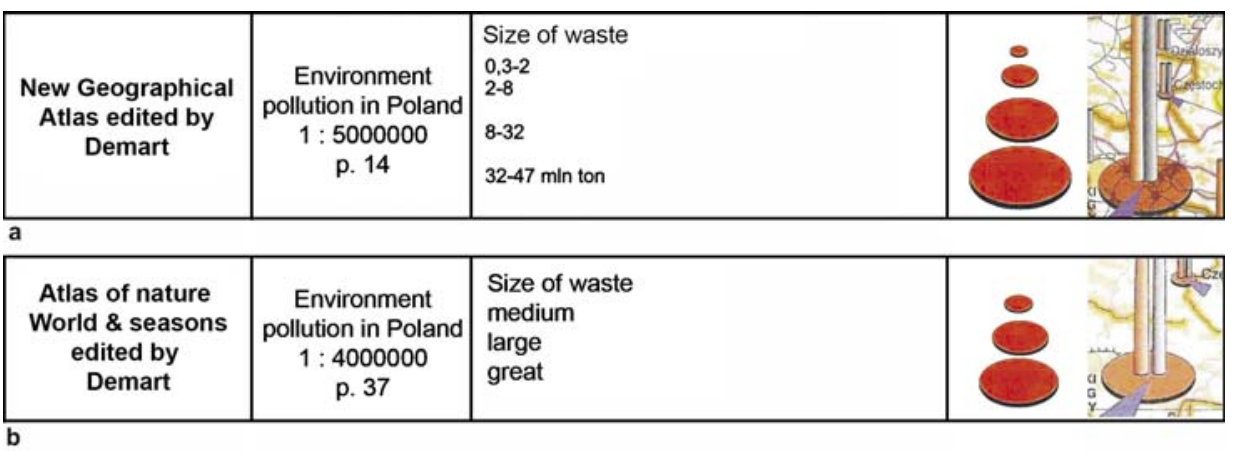

Fig. 5. Map with quantitative data for older students (a) and the same map with orginal data for younger student (b)

Ordinal methods are often used in the case of maps where quick reading and selecting some coded information, e.g. in the press, is the most important thing. The press map should be easy enough to read that one "eye-catch" be enough to comprehend the subject matter. We should not place difficult to read numbers or indicators on such maps. A simple map, with a clear graphic form, will definitely attract more attention (Fig. 6).

Application of ordinal methods allows for a certain generalization of the content. The cartographer groups some information and puts them in order already during mapping. In consequence, the map user has less problem with reading it. However, one may find in atlases such maps on which ordinal category application does not simplify the content (Fig. 7). Presentation of as many as eight ordinal categories and remembering them seems to be as difficult as remembering eight quantitative categories. 


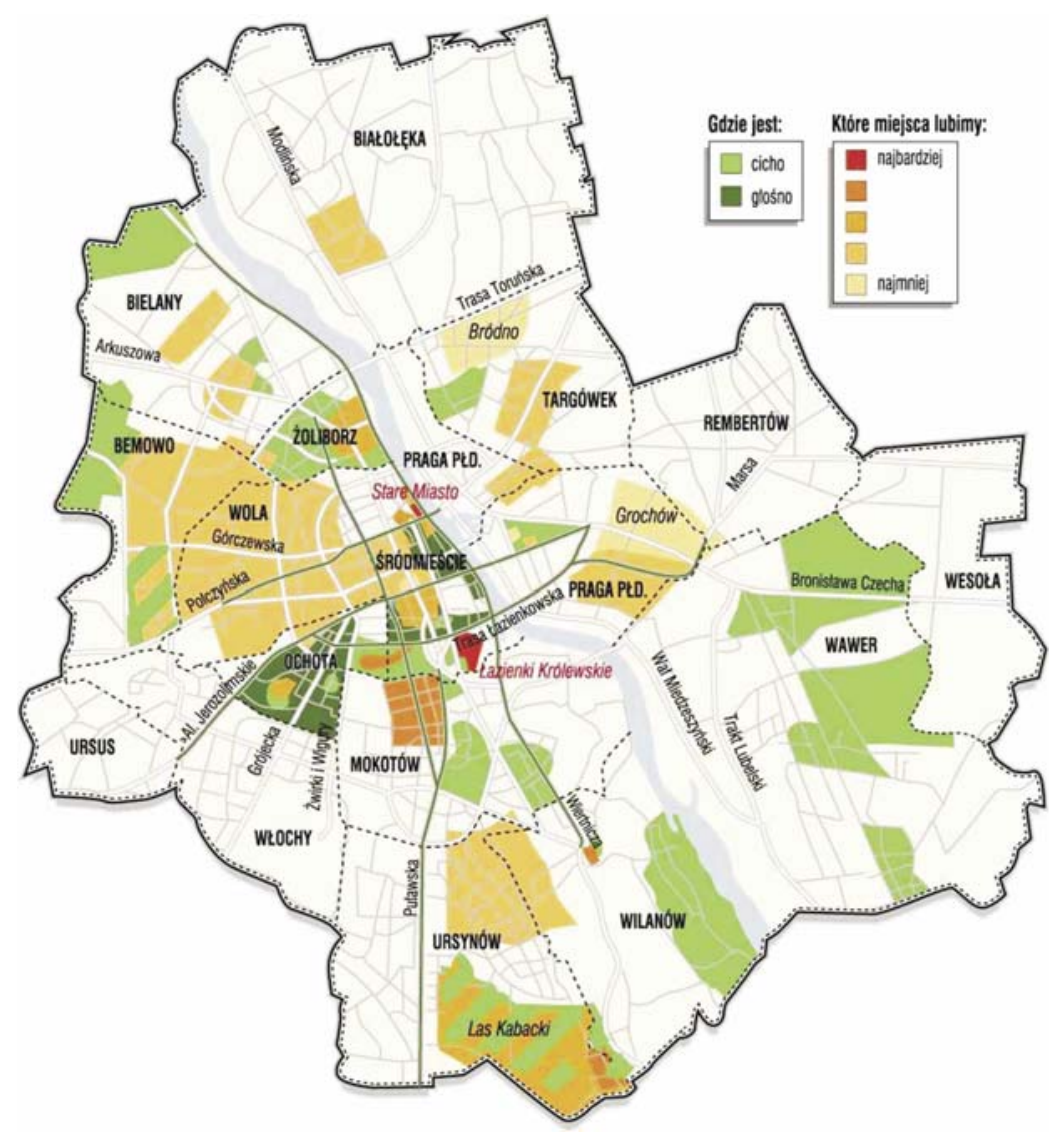

Fig. 6. Map with ordinal classification as a simple map with clear graphic

Besides the "new" ordinal methods we may also find in cartography a rather unusual application of the "old", well known and described cartographic methods. It is enough to recall the choropleth method to which much attention has been paid in cartographic literature. There were discussions about the class separation methods, types of data which may be presented in this way, about colour scales, the continuous and with intervals, simple and two-variable, choropleth map (J. Pasławski, 2003). In the meantime, in the practical category, there has appeared the thread of data relation (point or linear, not only aerial) associated with this method. Both in GIS programs and in cartographic publications linear choropleth map may be found (Fig. 8). 


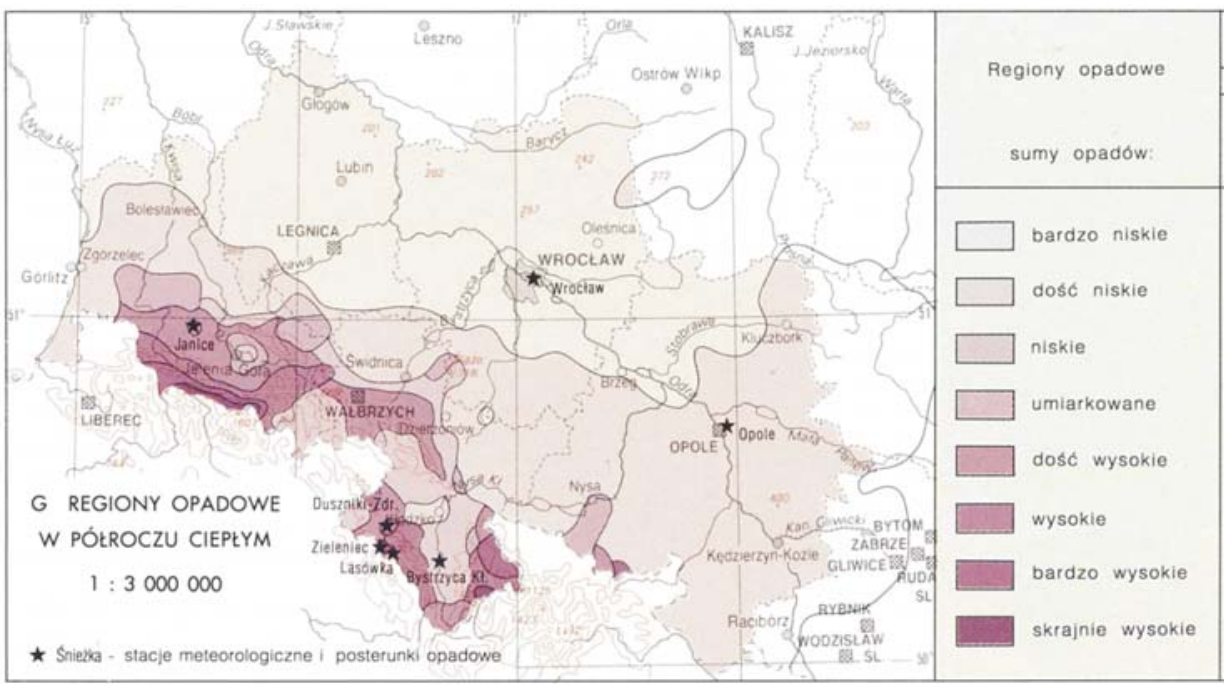

Fig. 7. Map with ordinal classification as a very complicated map

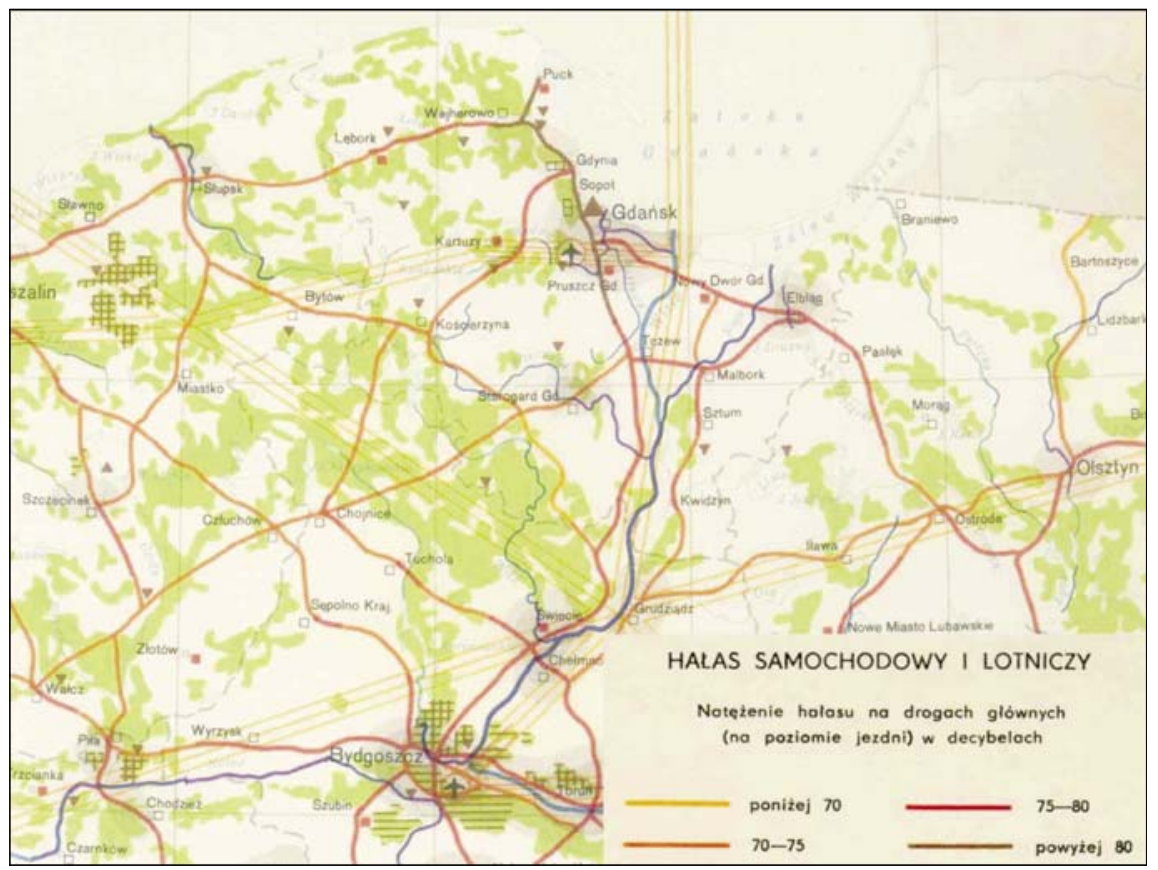

Fig. 8. Linear choropleth map 
Although the choropleth map shown in picture 8 is over 30 years old, this surely is a non-standard use of this method. The data related to lines have been shown by lines of the same width but with different colour. Such choropleth map may be elaborated in GIS programs, e.g. in MapInfo.

Further on, we may imagine a point choropleth map, in which data related to points and not to surface has been presented. On the map such data are presented by signs of the same size (circles, squares) or in diagrams in which size is the result of different data. The latter solution was used earlier in cartography. It was defined as the choropleth map based on a diagram (Fig. 9).

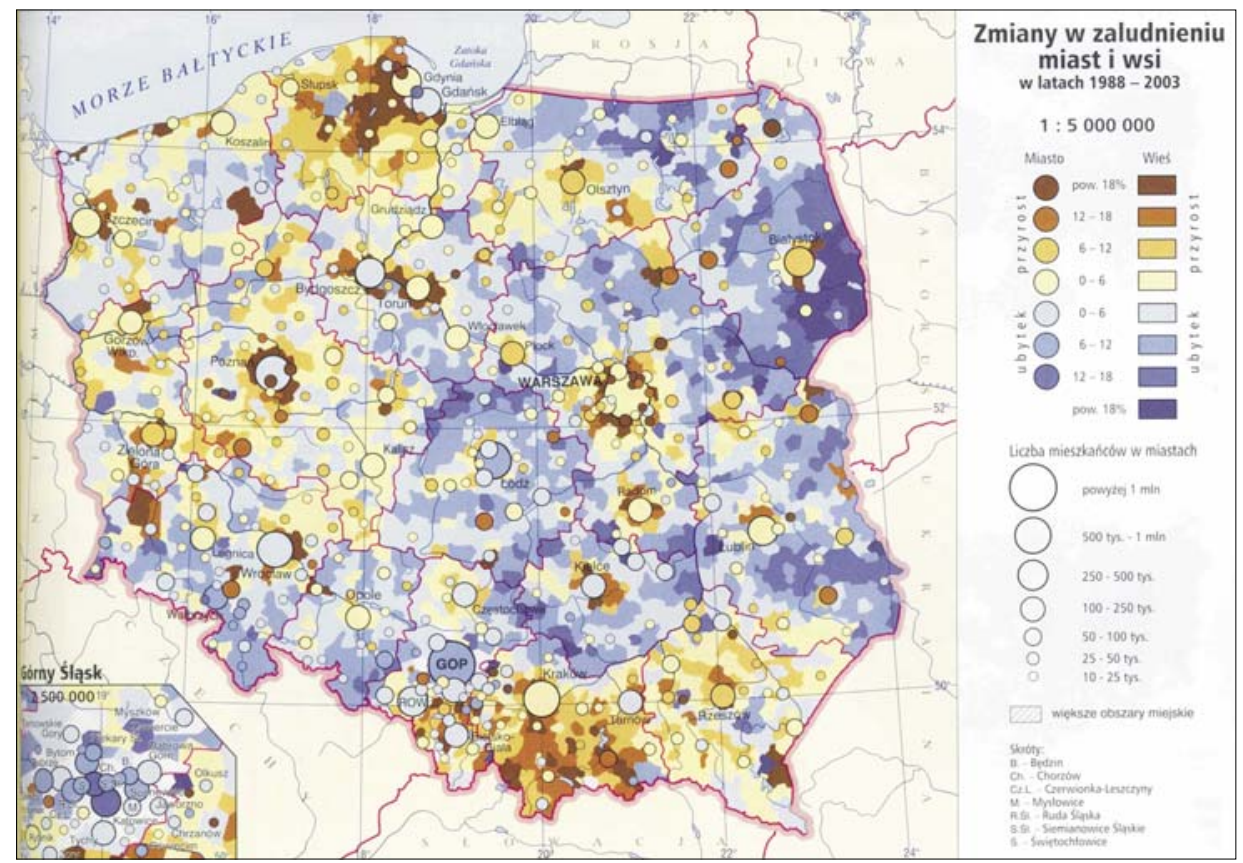

Fig. 9. Map with two layers of choropleth method. One related to circle diagrams

Till now, unquestionable was the fact that the choropleth map is an aerial method in which the data measured for particular surfaces are shown, e.g. units of administrative division or regular fields with a specific area. Meanwhile, it has been shown as well that datacan be counted for points or lines. 
We may find numerous examples of unusual application of the cartographic methods. But just few of them may be accepted by cartographers. Today, it is quite popular to use numbers on maps (Fig. 10). Instead of size or brightness which well express number relationships we can often see the numbers put into rectangles related to particular fields. It is difficult to label this solution as a cartographic method. This is just a table and its particular cells were placed on the map.

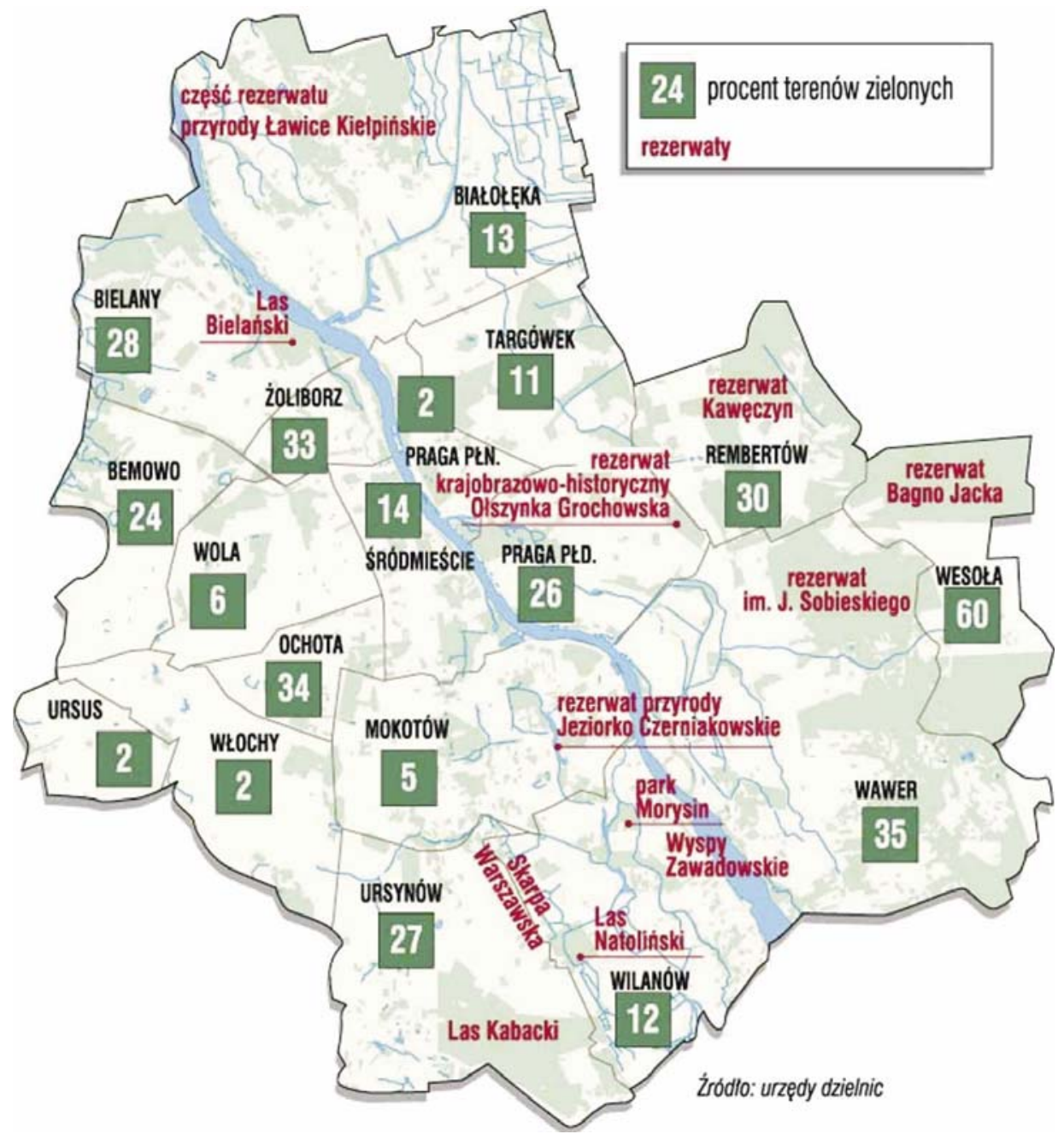

Fig. 10. Numbers on a map (percent of green areas) 
Cartography has opened its doors to non-cartographers. Nowadays, maps are elaborated by graphics, computer specialists and others who often have nothing in common with cartography, even with geography. It seems that there is an important challenge ahead of cartographers, i.e. to define with clarity the methods of cartographic presentation, to determine the requirements of a particular cartographic presentation and to undertake a new, successive attempt to classify them.

\section{REFERENCES}

Korycka-Skorupa J., 2002, Od danych do mapy. Część I. [From data to a map. Part I; in Polish], Polski Przeglad Kartograficzny T. 34, nr 2, 91-102.

Korycka-Skorupa J., 2002, Od danych do mapy. Część II. [From data to a map. Part II; in Polish], Polski Przeglad Kartograficzny T. 34, nr 2, 175-188.

Pasławski J., 2003, Jak opracować kartogram [How to make a choropleth map, in Polish], Warszawa: Uniwersytet Warszawski, Wydział Geografii i Studiów Regionalnych.

Ratajski L., 1973, Metodyka kartografii społeczno-gospodarcze [The socio-economic cartography methodology; in Polish], Warszawa: PPWK.

English translation: Izabeal Kacprzyk, Małgorzata Miłaszewska 